\title{
Carnobacterium inhibens isolated in blood culture of an immunocompromised, metastatic cancer patient: a case report and literature review
}

\author{
Carson Ka-Lok Lo ${ }^{1 *}$ id and Prameet M. Sheth ${ }^{2,3^{*}}$
}

\begin{abstract}
Background: Carnobacterium species are lactic acid-producing Gram-positive bacteria that have been approved by the US Food and Drug Administration and Health Canada for use as a food bio-preservative. The use of live bacteria as a food additive and its potential risk of infections in immunocompromised patients are not well understood.

Case presentation: An 81-year-old male with a history of metastatic prostate cancer on androgen deprivation therapy and chronic steroids presented to our hospital with a 2-week history of productive cough, dyspnea, altered mentation, and fever. Extensive computed tomography imaging revealed multifocal pneumonia without other foci of infection. He was diagnosed with pneumonia and empirically treated with ceftriaxone and vancomycin. Blood cultures from admission later returned positive for Carnobacterium inhibens. He achieved clinical recovery with stepdown to oral amoxicillin/clavulanic acid for a total 7-day course of antibiotics.

Conclusions: This is the fourth reported case of bacteremia with Carnobacterium spp. isolated from humans. This case highlights the need to better understand the pathogenicity and disease spectrum of bacteria used in the food industry for bio-preservation, especially in immunocompromised patients.
\end{abstract}

Keywords: Bacteremia, Carnobacterium inhibens, Carnobacterium species, Case report, Immunocompromised, Sepsis

\section{Background}

Carnobacterium species are lactic acid-producing, Gram-positive rod-shaped bacteria that are rarely isolated in humans and often regarded as non-pathogenic [1]. Instead, they are frequently isolated from the environment and are currently approved for use as a biopreservative in the food industry [1]. The use of live

\footnotetext{
* Correspondence: carson.lo@medportal.ca; prameet.sheth@queensu.ca ${ }^{1}$ Division of Infectious Diseases, Juravinski Cancer Centre, McMaster University Infectious Diseases Residency Program, 699 Concession Street, Hamilton, Ontario L8V 5C2, Canada

${ }^{2}$ Department of Pathology and Molecular Medicine, Queen's University, Kingston, Ontario, Canada

Full list of author information is available at the end of the article
}

bacteria as food additives poses a potential risk for immunocompromised patients, including several studies highlighting cases of bacteremia/sepsis associated with lactic acid bacteria used in probiotics (e.g., Lactobacillus spp.) [2-5].

We report a case of Carnobacterium inhibens isolated in blood culture of an immunocompromised cancer patient with pneumonia. We also reviewed published reports on human infections with Carnobacterium spp.

\section{Case presentation}

An 81-year-old male presented to the Emergency Department with a 2-week history of productive cough,

(c) The Author(s). 2021 Open Access This article is licensed under a Creative Commons Attribution 4.0 International License, which permits use, sharing, adaptation, distribution and reproduction in any medium or format, as long as you give appropriate credit to the original author(s) and the source, provide a link to the Creative Commons licence, and indicate if changes were made. The images or other third party material in this article are included in the article's Creative Commons licence, unless indicated otherwise in a credit line to the material. If material is not included in the article's Creative Commons licence and your intended use is not permitted by statutory regulation or exceeds the permitted use, you will need to obtain permission directly from the copyright holder. To view a copy of this licence, visit http://creativecommons.org/licenses/by/4.0/ The Creative Commons Public Domain Dedication waiver (http://creativecommons.org/publicdomain/zero/1.0/) applies to the data made available in this article, unless otherwise stated in a credit line to the data. 
exertional dyspnea, general malaise, altered mental status, and subjective fevers and chills. He had no recent sick contact exposures or travel history. He had no (farm) animal exposures and no history of the handling of, or heavy consumption of fish, dairy or meat products. His past medical history included castrate-resistant prostate cancer with liver and bone metastases on enzalutamide, leuprolide, and oral prednisone (10 $\mathrm{mg}$ daily) for at least 1 year. He also had triple-bypass cardiac surgery for a previous myocardial infarction. He had a previous history of smoking but no alcohol or recreational drug use.

On examination, his body temperature was $37.5^{\circ} \mathrm{C}$, with sinus tachycardia at 135 beats per minute, and blood pressure of $95 / 62 \mathrm{mmHg}$ which improved to 121 / $79 \mathrm{mmHg}$ with intravenous fluid resuscitation. He had a resting pulse oximeter saturation $\left(\mathrm{SpO}_{2}\right)$ nadir of $93 \%$ on room air, but continued to require supplemental oxygen by nasal cannula due to intermittent episodes of desaturations. Lung auscultation demonstrated decreased air entry to the bases with diffuse crackles bilaterally. No murmurs on cardiac auscultation or other stigmata of endocarditis.

Sepsis workup showed peripheral white blood cell count of $10.7 \times 10^{9} / \mathrm{L}$ with neutrophil count of $9.49 \times$
$10^{9} / \mathrm{L}$ and elevated inflammatory markers (erythrocyte sedimentation rate $90 \mathrm{~mm} / \mathrm{hr}$., C-reactive protein 195.9 $\mathrm{mg} / \mathrm{L}$ ). Blood cultures were obtained prior to antibiotic administration on admission. Chest radiograph followed by a full-body computerized tomography revealed multifocal pneumonia without other foci of infection. Transthoracic echocardiography did not show any vegetations or hemodynamically significant valvular dysfunctions. A bone scintigraphy revealed prior known bony metastases without other foci of infection.

Given concerns for clinical deterioration and sepsis, he was admitted to hospital and started on empiric antibiotics of ceftriaxone and vancomycin for pneumonia, potentially secondary to aspiration. Two of 4 blood culture bottles (i.e., both aerobic and anaerobic bottles) flagged positive at $18 \mathrm{~h}$ with a Gram-positive bacillus that failed to identify by the VITEK-MS MALDI-TOF (Matrix-Assisted Laser Desorption Time-Of-Flight Mass Spectrometry, bioMérieux Clinical Diagnostics, Canada). The isolate was forwarded to the provincial reference laboratory (Public Health Ontario Laboratory, PHOL) for further testing and identification. The isolate was identified by PHOL to be $C$. inhibens with homology of 99\% using 16S rRNA gene sequence analysis (Fig. 1a-d), though this information was only available after the patient was discharged home.

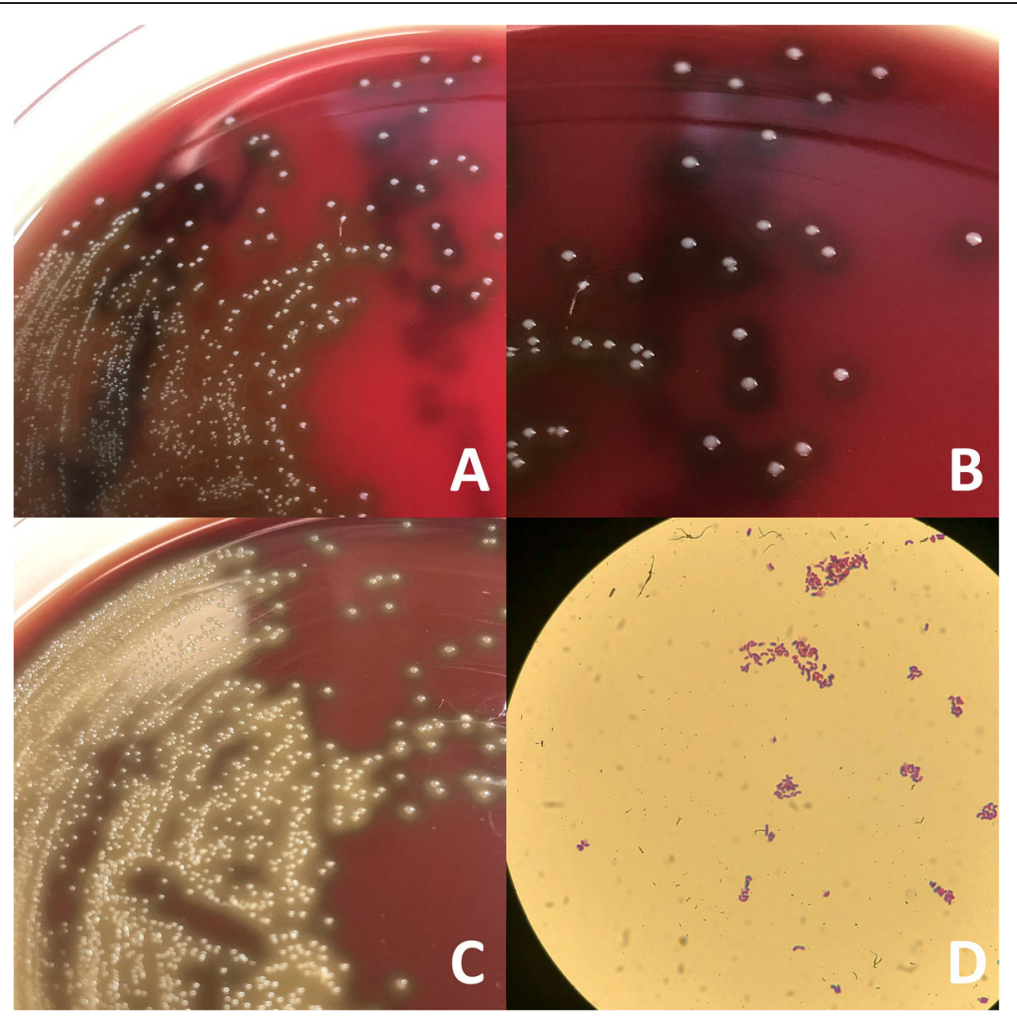

Fig. 1 Carnobacterium inhibens isolated after incubation at $37^{\circ} \mathrm{C}$ for $18 \mathrm{~h}$. a, b $1-2 \mathrm{~mm}$ diameter, grey-colored, round, alpha-hemolytic colonies on 5\% sheep blood agar. c Grey-colored, flat colonies surrounded by greenish discoloration around the colonies on chocolate agar. $\mathbf{d}$ Gram staining of blood culture isolate of C. inhibens depicting Gram-positive, asporogenous, lactobacillus-like rods, 100x 
The patient clinically improved with the empiric antibiotic regimen and was stepped down to oral amoxicillin/clavulanic acid for a total 7-day course of antibiotics. He achieved complete clinical recovery upon finishing antibiotics and did not require any supplemental oxygen at the time of discharge. Repeat blood cultures obtained both while on antibiotics and after discharge from hospital were negative.

\section{Discussion and conclusions}

Carnobacterium spp. belong to the order of lactic acid bacteria known as Lactobacillales, which includes genera such as Lactobacillus often seen in probiotic use [6]. Carnobacterium spp. are non-spore-forming, lactic acidproducing, Gram-positive rod-shaped bacteria $[7,8]$. Most species can be found in both polar and temperate environments due to their cryophilic and cryotolerant properties; they can tolerate, grow, and reproduce at low temperatures (i.e., -20 to $\left.+10^{\circ} \mathrm{C}\right)[1,7,8]$. They are also known to tolerate high-pressure environments, such as the vacuum-packing process in food preservation [9-11].

The use of live lactic acid-producing bacteria such as Carnobacterium spp. in food and bio-preservation continues to be a growing area of research in the meat, dairy and seafood industry. Bacteriocins produced by these bacteria have antimicrobial properties that limit or inhibit the growth of foodborne pathogens [1]. In particular, bacteriocins produced by the species $C$. divergens and $C$. maltaromaticum are shown to inhibit the growth of Listeria monocytogenes in various food products $[1,12]$. The additional unique properties of
Carnobacterium spp. to survive under high-pressure vacuum-packing and grow at refrigeration temperatures make them the ideal candidate as an additive to prevent food spoilage, especially in the meat and seafood industry [1]. Both $C$. divergens and C. maltaromaticum are currently approved by Health Canada as food additives for biopreservation of ready-to-eat smoked fish and vacuumpacked meat and poultry, respectively [13, 14]. Carnobacterium spp. are also used in the dairy industry and have been shown to reduce the growth of both $L$. monocytogenes and Pseudomonas spp. in soft unpasteurized cheeses, improving the safety and shelf-life of selected dairy products $[15,16]$.

Carnobacterium spp. are often considered non-pathogenic to humans [1]. Although the use of live lactic acid bacteria (e.g., Lactobacillus spp.) in probiotics has been approved by organizations such as the US Food and Drug Administration, current studies on its safety outcomes in immunocompromised populations remain limited [4]. Despite historical evidence of its safe use, recent studies have reported cases of infections associated with lactic acid bacteria used in probiotics [2-5]. For example, Lactobacillus spp. have been identified as the causal pathogen in several case reports, ranging from local (e.g., pneumonia, abscesses) to systemic infections (e.g., infective endocarditis, bacteremia and/or sepsis) [2-5]. To date, there are few studies on infections associated with Carnobacterium spp. in humans.

We performed a comprehensive search of all Englishwritten articles published on human infections with Carnobacterium spp. isolated from any body site or culture. We searched for articles from inception to December

Table 1 Literature review of human infections with Carnobacterium spp. isolated in cultures

\begin{tabular}{|c|c|c|c|c|c|c|c|c|c|}
\hline Case & $\begin{array}{l}\text { Age/ } \\
\text { Sex }\end{array}$ & Country & $\begin{array}{l}\text { Possible risk } \\
\text { factors }\end{array}$ & $\begin{array}{l}\text { Type of } \\
\text { culture/ } \\
\text { body Site } \\
\end{array}$ & Isolate & Presentation & Treatment & Outcome & Reference \\
\hline 1 & $\begin{array}{l}35 / \\
M\end{array}$ & $\begin{array}{l}\text { Czech } \\
\text { Republic }\end{array}$ & None & $\begin{array}{l}\text { Wound } \\
\text { swab of } \\
\text { abscess }\end{array}$ & $\begin{array}{l}\text { Mixed flora } \\
\text { with C. piscicola }\end{array}$ & $\begin{array}{l}\text { Traumatic hand from water } \\
\text { sawmill }\end{array}$ & $\begin{array}{l}\text { Amputation, } \\
\text { debridement; } \\
\text { Abx }\end{array}$ & Cured & {$[17]$} \\
\hline 2 & $13 / F$ & China & None & $\begin{array}{l}\text { Wound } \\
\text { swab of } \\
\text { gangrene }\end{array}$ & $\begin{array}{l}\text { Mixed flora } \\
\text { with } \\
\text { Carnobacterium } \\
\text { spp. }\end{array}$ & $\begin{array}{l}\text { Traumatic hand with pool water } \\
\text { exposure }\end{array}$ & $\begin{array}{l}\text { Amputation, } \\
\text { debridement; } \\
\text { IPM }\end{array}$ & Cured & [18] \\
\hline 3 & $\begin{array}{l}43 / \\
M\end{array}$ & Austria & $\begin{array}{l}\text { Extensive hx of } \\
\text { handling and } \\
\text { consuming fish }\end{array}$ & $\begin{array}{l}1 / 2 \text { blood } \\
\text { culture } \\
\text { sets }\end{array}$ & $\begin{array}{l}\text { C. mobile or } \mathrm{C} \text {. } \\
\text { funditum }\end{array}$ & Sepsis suspected from Gl source & $\begin{array}{l}\text { CRO/AMP } \rightarrow \\
\mathrm{MXF}\end{array}$ & Cured & [19] \\
\hline 4 & $57 / F$ & France & $\begin{array}{l}\mathrm{DM} ; \mathrm{EtOH} ; \mathrm{TPN} ; \\
\text { post-cardiac arrest }\end{array}$ & $\begin{array}{l}4 \text { blood } \\
\text { culture } \\
\text { sets }\end{array}$ & C. divergens & $\begin{array}{l}\text { Septic shock post-cardiac arrest; } \\
\text { esophagectomy for necrotizing } \\
\text { esophagitis on TPN/EN }\end{array}$ & $\begin{array}{l}\text { Broad } \\
\text { spectrum Abx } \\
\rightarrow \mathrm{AMX}\end{array}$ & Cured & {$[20]$} \\
\hline 5 & $\begin{array}{l}65 / \\
M\end{array}$ & $\begin{array}{l}\text { South } \\
\text { Korea }\end{array}$ & $\begin{array}{l}\text { Cancer; } \\
\text { neutropenia on } \\
\text { etoposide }\end{array}$ & $\begin{array}{l}1 / 2 \text { blood } \\
\text { culture } \\
\text { sets }\end{array}$ & C. divergens & $\begin{array}{l}\text { Febrile neutropenia with oral } \\
\text { mucositis on TPN }\end{array}$ & TZPNAN & Cured & {$[21]$} \\
\hline 6 & $\begin{array}{l}81 / \\
M\end{array}$ & Canada & $\begin{array}{l}\text { Cancer; chronic } \\
\text { steroid use }\end{array}$ & $\begin{array}{l}1 / 2 \text { blood } \\
\text { culture } \\
\text { sets }\end{array}$ & C. inhibens & Sepsis with multifocal pna & $\begin{array}{l}\text { CRONAN } \rightarrow \\
\text { AMC }\end{array}$ & Cured & Our case \\
\hline
\end{tabular}

Age (years old) and sex (F, female; $M$, male). Abbreviations: Abx antibiotics (not specified), $A M C$ amoxicillin/clavulanic acid, $A M P$ ampicillin, $A M X$ amoxicillin, $C R O$ ceftriaxone, DM diabetes mellitus, EN enteral nutrition, EtOH chronic alcohol use, Gl gastrointestinal, $h x$ history, IPM imipenem, MXF moxifloxacin, pna pneumonia, TPN total parenteral nutrition, TZP piperacillin-tazobactam, VAN vancomycin, $1 / 21$ of 2 positive culture sets 
2020 using databases including OvidMEDLINE, EMBASE (Additional files 1 and 2 for search strategy), and Google Scholar. To date, only 5 cases of Carnobacterium spp. isolated from humans have been reported (Table 1). Two cases had Carnobacterium spp. identified amongst mixed flora containing other aerobic and anaerobic bacteria from traumatic wounds, in the setting of water exposure $[17,18]$. Three cases were isolated from blood cultures; one was reported as suspected gastrointestinal source of infection in an immunocompetent man with 1 positive blood culture set who presented with fever and an extensive history of handling and consuming fish [19]. The remaining 2 cases were likely suspected gastrointestinal source or central line-associated bloodstream infection: a woman with diabetes and chronic alcohol use requiring parenteral nutrition postesophagectomy for necrotizing esophagitis complicated by post-operative cardiac arrest and septic shock, with multiple positive blood cultures for C. divergens [20], and; a man receiving chemotherapy and parenteral nutrition presenting with febrile neutropenia and extensive oral mucositis with 1 positive blood culture set for $C$. divergens [21].

Our case described an immunocompromised cancer patient on chronic steroids presenting with multifocal pneumonia with $C$. inhibens isolated in 2 of 4 blood culture bottles. Given the lack of clinical experience with this pathogen and its ability to cause disease in humans, as well the fact that $C$. inhibens was only isolated in 1 of 2 blood culture sets (with negative repeat blood cultures on antibiotics), there remained uncertainty whether it was the causative pathogen for the patient's pneumonia or a contaminant. Our case was unique as unlike other published cases, there was no clear exposure history, prior traumatic wounds, central venous catheter access (for parenteral nutrition), or excessive consumption of meat, dairy or seafood products. Extensive investigations by imaging confirmed pneumonia as the primary infection, without other foci of infection. Given the altered mentation, we suspect our patient aspirated giving rise to multifocal pneumonia, due to mixed aerobic and anaerobic bacteria from oral and/or gastric flora. We postulate the mixed flora likely included C. inhibens, which was later isolated in blood culture during transient bacteremia secondary from aspiration pneumonia. Although invasive procedures for culture (e.g., bronchoalveolar lavage) were not pursued to confirm our hypothesis as patient improved on empiric antibiotic therapy, we believe the pneumonia was likely polymicrobial as opposed to $C$. inhibens as sole pathogen responsible for causing infection.

To date, there are no recommended interpretative criteria or breakpoints established by the Clinical and Laboratory
Standards Institute (CLSI) for the susceptibility testing of antimicrobial agents against Carnobacterium spp. causing human infections. Some of the cases reported the minimum inhibitory concentration (MIC) of their isolates, which seemed to suggest susceptibility to penicillins, carbapenems, macrolides, but resistance to cephalosporins $[19,20]$. Certain Carnobacterium spp. isolates such as C. piscicola demonstrated intrinsic resistance to many antibiotics including fluoroquinolones, aminoglycosides, trimethoprim, though the mechanisms of resistance remain not well understood [22]. In vitro susceptibilities to antibiotic classes including penicillins also varied across different Carnobacterium spp. strains [22-24]. Drug susceptibility testing performed on a C. inhibens strain in a 2002 study appeared to show in vitro sensitivity to several antibiotics including, but not limited to, penicillins, tetracycline, and vancomycin [24]. No susceptibility testing was performed for our isolate; our patient responded well to empiric parenteral followed by oral stepdown antibiotics for aspiration pneumonia, prior to confirmation of the $C$. inhibens isolate as it required identification at a reference laboratory. Future considerations of antibacterial susceptibility breakpoints can be revisited once a better understanding of the infections associated with Carnobacterium spp. has been established.

The pathogenicity and disease spectrum of Carnobacterium spp. in humans remain unknown. The use of Gram-positive bacteria in the food industry for their bio-preservative or fermentative capacity presents a potential source of unique organisms leading to disease, especially in immunocompromised patients.

\section{Abbreviations \\ C. divergens: Carnobacterium divergens; C. funditum: Carnobacterium funditum; C. inhibens: Carnobacterium inhibens; C. maltaromaticum: Carnobacterium maltaromaticum; C. mobile: Carnobacterium mobile; C. \\ piscicola: Carnobacterium piscicola; CLSI: Clinical and Laboratory Standards Institute; L. monocytogenes: Listeria monocytogenes; MALDI-TOF-MS: Matrix- Assisted Laser Desorption Time-Of-Flight Mass Spectrometry; MIC: Minimum inhibitory concentration; PHOL: Public Health Ontario Laboratory; 16S rRNA gene sequence analysis: $16 \mathrm{~S}$ ribosomal RNA gene sequence analysis}

\section{Supplementary Information}

The online version contains supplementary material available at https://doi. org/10.1186/s12879-021-06095-7.

Additional file 1. Database: OVID Medline Epub Ahead of Print, InProcess \& Other Non-Indexed Citations, Ovid MEDLINE(R) Daily and Ovid MEDLINE(R) 1946 to Present - Search Strategy. Compilation of search strategy, search key terms, and full list of journal article titles and abstracts from initial literature search of Ovid MEDLINE database (inception to December 2020); list was used for screening of relevant articles for subsequent literature review (Table 1).

Additional file 2. Database: Embase <1974 to 2020 December 29> Search Strategy. Compilation of search strategy, search key terms, and full list of journal article titles and abstracts from initial literature search of EMBASE database (inception to December 2020); list was used for screening of relevant articles for subsequent literature review (Table 1). 


\section{Acknowledgements}

We would like to thank our colleagues from the Division of Microbiology, Kingston Health Sciences Centre, for kindly preparing and isolating the Carnobacterium spp. strain for visualization.

\section{Authors' contributions}

CKL performed the literature review and drafted the manuscript. CKL and PMS critically reviewed and substantively revised the manuscript. PMS provided supervision and academic advice for CKL. All authors have read and approved the final manuscript.

\section{Funding}

This research did not receive any specific funding.

\section{Availability of data and materials}

All data generated and/or analysed during this study are included in this published article [and its supplementary information files]. Please see Table 1 for data extracted from literature review and Additional file 1 and Additional file 2 for our literature search strategies from databases.

\section{Declarations}

\section{Ethics approval and consent to participate}

Ethical approval was obtained from Queen's University Health Sciences \& Affiliated Teaching Hospitals Research Ethics Board (HSREB). Written informed consent was obtained from the patient's family.

\section{Consent for publication}

Written informed consent was obtained from the patient's family for publication of this case report and any accompanying images. A copy of the written consent is available for review by the Editor of this journal.

\section{Competing interests}

The authors declare that they have no competing interests.

\section{Author details}

'Division of Infectious Diseases, Juravinski Cancer Centre, McMaster University Infectious Diseases Residency Program, 699 Concession Street, Hamilton, Ontario L8V 5C2, Canada. ${ }^{2}$ Department of Pathology and Molecular Medicine, Queen's University, Kingston, Ontario, Canada. ${ }^{3}$ Division of Microbiology, Kingston Health Sciences Centre, 76 Stuart Street, Kingston, Ontario K7L 2V7, Canada.

\section{Received: 3 February 2021 Accepted: 20 April 2021}

Published online: 01 May 2021

\section{References}

1. Leisner JJ, Laursen BG, Prévost H, Drider D, Dalgaard P. Carnobacterium: positive and negative effects in the environment and in foods. FEMS Microbiol Rev. 2007;31(5):592-613. https://doi.org/10.1111/j.1574-6976.2007.00080.x

2. Castro-González JM, Castro P, Sandoval H, Castro-Sandoval D. Probiotic lactobacilli precautions. Front Microbiol. 2019;10(375):1-5. https://doi.org/1 0.3389/fmicb.2019.00375

3. Costa RL, Moreira J, Lorenzo A, Lamas CC. Infectious complications following probiotic ingestion: a potentially underestimated problem? A systematic review of reports and case series. BMC Complement Altern Med. 2018;18(1):329. https://doi.org/10.1186/s12906-018-2394-3.

4. Doron S, Snydman DR. Risk and safety of probiotics. Clin Infect Dis. 2015; 60(suppl_2):S129-S34. https://doi.org/10.1093/cid/civ085.

5. Kothari D, Patel S, Kim S-K. Probiotic supplements might not be universallyeffective and safe: a review. Biomed Pharmacother. 2019;111:537-47. https:// doi.org/10.1016/j.biopha.2018.12.104.

6. Makarova KS, Koonin EV. Evolutionary genomics of lactic acid bacteria. J Bacteriol. 2007;189(4):1199-208. https://doi.org/10.1128/JB.01351-06.

7. Collins MD, Farrow JAE, Phillips BA, Ferusu S, Jones D. Classification of lactobacillus divergens, lactobacillus piscicola, and some catalase-negative, asporogenous, rod-shaped bacteria from poultry in a new genus, carnobacterium. Int J Syst Evol Microbiol. 1987;37(4):310-6. https://doi.org/1 0.1099/00207713-37-4-310.
8. Jöborn A, Dorsch M, Olsson JC, Westerdahl A, Kjelleberg S. Carnobacterium inhibens sp. nov., isolated from the intestine of Atlantic salmon (Salmo salar). Int J Syst Evol Microbiol. 1999:49(4):1891-8. https://doi.org/10.1099/00207713-49-4-1891.

9. Lakshmanan R, Dalgaard P. Effects of high-pressure processing on Listeria monocytogenes, spoilage microflora and multiple compound quality indices in chilled cold-smoked salmon. J Appl Microbiol. 2004;96(2):398-408. https://doi.org/10.1046/j.1365-2672.2004.02164.x.

10. Lauro FM, Chastain RA, Blankenship LE, Yayanos AA, Bartlett DH. The unique $16 S$ rRNA genes of piezophiles reflect both phylogeny and adaptation. Appl Environ Microbiol. 2007;73(3):838-45. https://doi.org/10.1128/AEM.01726-06.

11. Paarup T, Sanchez JA, Peláez C, Moral A. Sensory, chemical and bacteriological changes in vacuum-packed pressurised squid mantle (Todaropsis eblanae) stored at $4{ }^{\circ} \mathrm{C}$. Int J Food Microbiol. 2002;74(1):1-12. https://doi.org/10.1016/S0168-1605(01)00701-2.

12. Brillet A, Pilet M-F, Prevost $H$, Bouttefroy A, Leroi F. Biodiversity of Listeria monocytogenes sensitivity to bacteriocin-producing Carnobacterium strains and application in sterile cold-smoked salmon. J Appl Microbiol. 2004;97(5): 1029-37. https://doi.org/10.1111/j.1365-2672.2004.02383.x.

13. Notice of Health Canada's proposal to enable the use of a new food additive, Carnobacterium divergens M35, as an antimicrobial preservative in sliced ready-to-eat cold-smoked salmon and sliced ready-to-eat coldsmoked trout - NOP/AVP-0018 [https://www.canada.ca/en/health-canada/ services/food-nutrition/public-involvement-partnerships/proposal-use-newfood-additive-carnobacterium-divergens-antimicrobial-preservative-sliced-rea dy-cold-smoked-salmon-sliced.html]. Accessed 4 July 2020.

14. Notice of modification to the list of permitted preservatives to enable the use of Carnobacterium maltaromaticum CB1 as an antimicrobial preservative in certain meat and poultry meat products reference number: NOM/ADM-0097. [https://www.canada.ca/en/health-canada/services/food-nutrition/publicinvolvement-partnerships/notice-modification-list-permitted-preservatives-ena ble-use-carnobacterium-maltaromaticum-cb1-antimicrobial-preservative-certa in-meat-poultry-meat.html]. Accessed 4 July 2020.

15. Hammi I, Delalande F, Belkhou R, Marchioni E, Cianferani S, Ennahar S. Maltaricin CPN, a new class lla bacteriocin produced by Carnobacterium maltaromaticum CPN isolated from mould-ripened cheese. J Appl Microbiol 2016;121(5):1268-74. https://doi.org/10.1111/jam.13248.

16. Spanu C, Piras F, Mocci AM, Nieddu G, De Santis EPL, Scarano C. Use of Carnobacterium spp protective culture in MAP packed ricotta fresca cheese to control Pseudomonas spp. Food Microbiol. 2018;74:50-6. https://doi. org/10.1016/j.fm.2018.02.020.

17. Chmelař D, Matušek A, Korger J, Durnová E, Steffen M, Chmelařová E. Isolation of Carnobacterium piscicola from human pus — case report. Folia Microbiol (Praha). 2002;47(4):455-7. https://doi.org/10.1007/BF02818708.

18. Xu J, Yang H, Lai X, Fu X, Wu J, Huang L, et al. Etiological study for a case of multi-bacterial synergistic gangrene. Chin Sci Bull. 1997;42(6):511-7. https:// doi.org/10.1007/BF02882606

19. Hoenigl M, Grisold AJ, Valentin T, Leitner E, Zarfel G, Renner H, et al Isolation of Carnobacterium sp. from a human blood culture. J Med Microbiol. 2010;59(4):493-5. https://doi.org/10.1099/jmm.0.016808-0.

20. Smati M, Palacios C, Cohen Y, Méchaï F, Tankovic J, Le Flèche-Mateos A, et al. Carnobacterium divergens bacteremia in woman. Emerg Infect Dis. 2015;21(6):1081-2. https://doi.org/10.3201/eid2106.141799.

21. Jeong $\mathrm{H}-\mathrm{H}$, Ahn G-D, Kim N-H, Kim K-H, Shin S-D, Han J-Y, et al. Isolation of Carnobacterium divergens from blood culture in Korea: a case report and literature review. Ann Clin Microbiol. 2020;23(3):209-13. https://doi.org/10. 5145/ACM.2303.23.3.4

22. Baya AM, Toranzo AE, Lupiani B, Li T, Roberson BS, Hetrick FM. Biochemical and serological characterization of Carnobacterium spp. isolated from farmed and natural populations of striped bass and catfish. Appl Environ Microbiol. 1991; 57(11):3114-20. https://doi.org/10.1128/AEM.57.11.3114-3120.1991.

23. Lai S, Manchester LN. Numerical phenetic study of the genus Carnobacterium. Antonie Van Leeuwenhoek. 2000;78(1):73-85. https://doi. org/10.1023/A:1002723609675.

24. Ringø E, Seppola M, Berg A, Olsen RE, Schillinger U, Holzapfel W. Characterization of Carnobacterium divergens strain 6251 isolated from intestine of Arctic charr (Salvelinus alpinus L.). Syst Appl Microbiol. 2002; 25(1):120-9. https://doi.org/10.1078/0723-2020-00080.

\section{Publisher's Note}

Springer Nature remains neutral with regard to jurisdictional claims in published maps and institutional affiliations. 